\title{
El proceso de modernización administrativa contenido en la LOFAGE
}

Luis Ortega *

\section{Introducción}

La nueva regulación de la organización y funcionamiento de la Administración General del Estado ' (2) tiene sus orígenes en el proceso de modernización de la Administración del Estado que ha venido planteándose, tanto por la doctrina científica como por la clase política, en las últimas décadas de nuestra historia reciente. Existían, en efecto, tres elementos estructurales que hacían necesario un cambio normativo en lo que se refiere a la organización y funcionamiento de la Administración estatal. De un lado, las nuevas bases constitucionales aplicables a las Administraciones Públicas, entre las que podemos encontrar là necesidad de distinguir las funciones de dirección política del Gobierno como órgano constitucional de las funciones ejecutivas de la Administración General del Estado, o la aplicación de los nuevos principios de eficiencia y eficacia. En segundo lugar, la nueva forma de Estado políticamente descentralizado, en la versión conocida en España como Estado de las Autonomías, planteaba la necesidad de modificar la forma de gestión y organización de la Administración estatal, especialmente en relación a sus órganos periféricos en virtud de la aparición de las nuevas Administraciones autonómicas y del otorgamiento del principio de autonomía a las Administraciones locales. Finalmente, la definición de España, como un Estado social y la progresiva implantación de servicios típicos del Estado de bienestar que elevaron el gasto del sector público de 10,6 billones de pesetas en 1984 a 33,7 billones de pesetas en 1995, obligan a dar una mayor relevancia a la gestión de prestación frente a la tradicional gestión de autoridad.

La normativa existente hasta la reciente LOFAGE provenía, en parte, de la antigua Ley de Régimen Jurídico de la Admi- nistración del Estado de 26 de julio de 1957 y de la Ley de Entidades Estatales Autónomas de 26 de diciembre de 1958, con las modificaciones introducidas por la Ley 10/1983, de 16 de agosto, de Organización de la Administración Central del Estado; por la Ley 17/83, de 16 de noviembre, sobre Delegados del Gobiemo en las Comunidades Autónomas; por el R.D. 3117/1980, de 22 de diciembre, del Estatuto de los Gobernadores Civiles; y por la Ley General Presupuestaria de 23 de septiembre de 1988.

A partir de 1993, en la última legislatura del anterior Gobierno socialista, se inicia el proceso actual de reforma que tuvo su plasmación en el Proyecto de Ley de Organización y Funcionamiento de la Administración General del Estado ${ }^{2}$ que, en términos generales y con las adaptaciones que luego veremos, fue recogido por el nuevo Gobierno del Partido Popular y convertido en la actual Ley 6/1997 de idéntica denominación. Este hecho no nos debe pasar desapercibido, pues significa que, en punto a la reforma de la Administración estatal, existe un alto grado de encuentro entre la izquierda y la derecha española, lo cual es un dato de gran relevancia en la historia de la Administración Pública española.

Sin ignorar este elemento objetivo, y sin pretender añadir ninguna suspicacia estéril hay que señalar que en la elaboración de esta Ley ha faltado desde el comienzo de sus trabajos en el período socialista el necesario impulso político para imponer los elementos de racionalidad de la reforma hasta sus últimas consecuencias. En efecto, los proyectos iniciales del Ministerio para las Administraciones Públicas tuvieron que enfrentarse con las posiciones del Ministerio de Economía y Hacienda y del Ministerio del Interior. Respecto del primero, se pretendía incluir en la LOFAGE elementos de flexibilización y agilización de la gestión presupuestaria dando más capacidad y autonomía a los Ministerios en la ejecución del gasto. Respecto 
del segundo, el problema central fue la delimitación de la dependencia de la Administración estatal en la Provincia, cuyas autoridades cumplen un papel decisivo en lo que se refiere al mando de las fuerzas y cuerpos de seguridad, tanto en lo relativo a su subordinación a los Delegados del Gobierno en las Comunidades Autónomas, como a su dependencia del Ministerio para las Administraciones Públicas. Ninguno de estos objetivos se ha conseguido plenamente, pero el resultado político que se produjo, ya con el Proyecto de Ley socialista, fue la existencia de un texto que, tras sus correspondientes menguas, había sido asumido ya por todos los Ministerios. Por eso, la nueva dirección del Ministerio de Administraciones Públicas se encuentra con una bicoca: un modelo de reforma de la Administración que ya ha sido asumido por la propia Administración.

De esta forma, cabe el riesgo de que nos encontremos con una Ley cuyos planteamientos últimos de transformación administrativa no cuenten con un gran impulso, más allá de la ganancia política que supone la aprobación de una nueva Ley. Le corresponde, así, tanto a la doctrina como a los aplicadores de la nueva Ley destacar los elementos de reforma que deben ser a todas luces impulsados para continuar los procesos de modernización de las Administraciones públicas.

Estos elementos de reforma para el nuevo modelo de organización y funcionamiento de la Administración estatal pueden ser cifrados en los siguientes:

- Unificar en un único texto el régimen jurídico común para todo tipo de Administraciones y entidades que hagan referencia a la dirección política del Gobierno de la Nación.

- Diferenciar el régimen jurídico del Gobiemo del de la Administración estatal.

- Dotar de una mayor flexibilidad a la organización de la Administración para hacerla compatible con la innumerable variedad de fines públicos que le son atribuidos por las normas.

- Introducir un nivel de dirección administrativa presidido por la nota de la profesionalidad.

- Adaptar el funcionamiento administrativo a los derechos reconocidos a los ciudadanos respecto de un determinado nivel de calidad de los servicios públicos.

- Adaptar la Administración periférica del Estado a la estructura del Estado de las Autonomías.

\section{La unificación normativa de la función ejecutiva estatal}

Unos de los objetivos de la reforma ha sido el de unificar en un único texto legal el régimen jurídico común al conjunto de Administraciones y entidades que hacen referencia a la función ejecutiva estatal. Se regula, así, la Administración General del Estado en su triple vertiente de Administración central, periférica y exterior y los Organismos Públicos que componen la Administración instrumental subdivididos en dos categorías esenciales, los Organismos Autónomos y las Entidades Públicas Empresariales.

Sin embargo, este intento goza de importantes excepciones que quiebran esta voluntad unificadora. Sin detenernos en la crítica de la regulación de la Administración en el exterior, cuyo régimen jurídico queda muy superficialmente reflejado, aparentando más un compromiso formal de regulación unificada que una integración normativa material, quedan fuera del ámbito de aplicación de la LOFAGE, en virtud de sus Disposiciones Adicionales, un importante conjunto de entes administrativos y de sectores de la organización: la Administración militar; el régimen de personal, económico-financiero, patrimonial, presupuestario y contable de las Entidades gestoras y la Tesorería General de la Seguridad Social; el Consejo de Estado; el Banco de España; la Agencia Estatal de la Administración Tributaria; el Consejo Económico y Social; el Instituto Cervantes; la Comisión Nacional del Mercado de Valores; el Consejo de Seguridad Nuclear; el Ente Público de Radio Televisión Española; las Universidades no transferidas; la Agencia de Protección de Datos; el Consorcio de la Zona Espacial de Canarias; la Comisión del Sistema Eléctrico Nacional y la Comisión del Mercado de las Telecomunicaciones.

Caben destacar, junto a la exclusión de la Administración militar, la referida a la Agencia Tributaria que constituye el brazo gestor del Ministerio de Hacienda, las Entidades y Tesorería de la Seguridad Social, que aleja de la aplicación de la Ley a casi la mitad del gasto público estatal, y a las Comisiones relativas al Mercado de Valores, al Sistema Eléctrico y al Mercado de las Telecomunicaciones, dado que tienen como significado la separación normativa de las denominadas Administraciones Independientes. Así, pese al esfuerzo que hace la Ley de crear un espacio de flexibilidad normativa con relación a los Organismos Públicos para integrarlos en la normativa común, cuando éstos tienen relación con aspectos importantes de la gestión económica o la intervención del Estado en la economía se abandona 
todo intento de integración dentro de los rasgos generales del funcionamiento administrativo.

\section{La diferenciación entre Gobierno y Administración Pública}

La diferenciación constitucional entre Gobierno (arts. 97 a 102) y Administración Pública (arts. 103 a 107) es uno de los objetivos de esta Ley que se complementa a estos efectos con un proyecto de Ley paralelo referido al Gobierno que se está tramitando actualmente en sede parlamentaria ${ }^{3}$.

Así, la cúspide de la organización administrativa termina según la LOFAGE en el Ministerio, mientras que desaparecen de la estructura administrativa otros órganos más avanzados en el proceso de toma de decisiones, como el Presidente del Gobierno, los Vicepresidentes, el Consejo de Ministros, las Comisiones Delegadas del Gobierno que pasan a ser exclusivamente órganos del Gobierno y la Comisión General de Secretarios de Estado y Subsecretarios, que para el Proyecto de Ley del Gobierno se configura fuera de la Administración como un órgano de apoyo del Gobierno.

La relación entre Administración y Gobierno gira en torno a la figura del Ministro, que reúne la doble condición de miembro del Gobiemo y órgano superior de la Administración en cuanto titular de un departamento ministerial cuya dirección le queda encomendada bajo su responsabilidad.

Tambien actúa como órgano de relación entre Administración y Gobierno el Secretario de Estado, que es calificado como órgano de apoyo al Gobierno, pero que no forma parte del mismo, por lo que formalmente se configura como un órgano administrativo, aunque materialmente ocupa una posición híbrida gubernamental-administrativa. Puede asistir, así, si es convocado, a las reuniones del Consejo de Ministros; también puede formar parte de las Comisiones Delegadas del Gobierno que es formalmente un órgano del Gobierno; e integra la Comisión General de Secretarios de Estado y Subsecretarios que estudia con carácter preparatorio los asuntos que serán sometidos al Consejo de Ministros. En el plano administrativo el Secretario es también un órgano superior de pura designación política colocado bajo la dependencia jerárquica del Ministro que tiene a su cargo un conjunto de Direcciones Generales que debe dirigir y coordinar.

Las figuras de los Subsecretarios, los Secretarios generales, los Secretarios generales técnicos, los Directores generales y los Subdirectores generales son consideradas ya definitivamente ór- ganos directivos de la Administración de los que se va a predicar un requisito de competencia profesional y experiencia previa para ser nombrados.

Además de la ambigüedad formal/material de la figura del Secretario de Estado, debe destacarse que algunas de las funciones atribuidas al Ministro en la LOFAGE tienen una mayor naturaleza de competencias de dirección política que de actuación administrativa, lo que en su día podrá provocar problemas de calificación jurídica a efectos del eventual control judicial de determinados actos.

Finalmente, cabe destacar una pequeña quiebra en el intento de trazar una clara línea divisoria entre Gobierno y Administración a la altura de los Ministerios. Esta quiebra se produce al considerar la posibilidad de que puedan adscribirse directamente Secretarías de Estado o cualquier órgano directivo e incluso Organismos Públicos al Presidente o a los Vicepresidentes del Gobierno. Cuando esto sucediese, se reabriría el problema de la naturaleza administrativa de las funciones presidenciales referidas a esas parcelas de la Administración.

\section{Flexibilidad organizativa acorde a la pluralidad de fines públicos}

La pluralidad de fines encomendados a las Administraciones Públicas, así como la regla constitucional (art. 128.2) que consagra la libre iniciativa pública en la actividad económica, exige flexibilizar los instrumentos organizativos para adaptarlos adecuadamente a las finalidades establecidas en las normas.

El modelo de reforma se ha planteado desde un principio la división de cuatro grandes grupos de actividades realizadas bajo la decisión pública, para los que prevé una forma organizativa determinada. El primer grupo lo constituyen las actividades puramente económicas para las cuales se predica la forma de Sociedad Mercantil regidas por el Derecho privado, excepto en lo referente a la aplicación de la normativa presupuestaria, contable, de control financiero y contratación. Expresamente queda prohibido que puedan disponer de facultades que impliquen el ejercicio de autoridad pública.

Precisamente, la posibilidad de que determinadas empresas públicas que actúen en el ámbito de las actividades económicas ejerzan al mismo tiempo determinadas potestades administrativas es el elemento que cualifica un segundo tipo organizativo: las Entidades Públicas Empresariales. Éstas se configuran como entes públicos regidos esencialmente por el Derecho privado, en lo que no 
afecte al ejercicio de dichas funciones administrativas, y cuya financiación debe obtenerse en aplicación de las reglas del mercado. Sólo excepcionalmente, y dentro del respeto a los artículos 90,92 , 93 y 94 del Tratado de la Comunidad Europea, su Ley de creación podrá autorizar una financiación a cargo de recursos públicos.

El tercer grupo lo constituyen aquellas actividades típicamente administrativas de las que se pretende una descentralización funcional que son organizadas bajo la figura del Organismo Autónomo. Su misión es, por tanto, la ejecución de un programa específico de la actividad de un Ministerio, por lo que, en teoría, toda la actividad de gestión administrativa encomendada a un Ministerio puede ser descentralizada por programas en estos Organismos, dejando al Ministerio reducido a una actividad de planificación, programación, dirección, control y evaluación de los Organismos que tuviese adscritos. En virtud de la especificidad de estos programas, la Ley de creación de dicho Organismo puede prever un régimen peculiar en materia de personal en lo relativo a la oferta de empleo, sistemas de acceso, adscripción y provisión de puestos y régimen de movilidad. Estos Organismos Autónomos cuentan, además, con una mayor autonomía en la administración de sus bienes patrimoniales.

Finalmente, la forma organizativa ministerial podría quedar reducida, como antes se aludía, a aquellas funciones típicamente gubernativas de apoyo a la toma de decisiones del Gobierno, de elaboración de proyectos normativos, de elaboración programática y de control de las funciones ejecutivas descentralizadas en los Organismos Públicos correspondientes. De este modo, la dimensión del Ministerio podría ser muy reducida, por lo que en el Proyecto de Ley socialista la estructura ministerial partía de una complejidad mínima constituida por el Ministro y dos Directores generales. Sin embargo, en la redacción final del actual Gobierno, la LOFAGE exige un mayor volumen burocrático, al establecerse como órganos necesarios del Ministerio la Subsecretaría y la Secretaría General Técnica, lo que hace prever que no es voluntad del actual Gobierno proceder de manera generalizada a una descentralización funcional de las competencias ministeriales en los Organismos Autónomos.

\section{La creación de un nivel de dirección administrativa profesionalizado}

Desde hace más de una década viene discutiéndose en España la conveniencia de convertir las Direcciones Generales, que tradicionalmente han sido cargos de designación política, en órganos administrativos que fuesen cubiertos por funcionarios como culmen de su carrera profesional. Esta idea fue incorporada desde el inicio del proceso de reforma que ha desembocado en la aprobación de la LOFAGE.

En la nueva Ley la profesionalización se predica en términos generales de todos los titulares de los órganos directivos recabando criterios de competencia profesional y experiencia, en función de los cuales le sea exigible una responsabilidad profesional, personal y directa por la gestión desarrollada y quedan sometidos al control y evaluación de dicha gestión por el órgano superior o directivo competente.

Estos requisitos generales tienen, sin embargo, una distinta gradación en relación a cada tipo de órgano directivo, donde se concreta si dicha experiencia ha sido adquirida como funcionario público exclusivamente o puede haberse adquirido en el sector privado.

Así, dentro de la Administración central los Subsecretarios y los Secretarios generales técnicos deben ser nombrados libremente entre funcionarios de carrera del Estado, de las Comunidades Autónomas o de las Entidades Locales a los que se exija para su ingreso el título de Doctor, Licenciado, Ingeniero, Arquitecto o equivalente. Los Secretarios generales, en cambio, deben haber sido personas con cualificación y experiencia en la gestión pública y privada. Los Directores generales tienen una exigencia mixta, ya que, en términos generales, deben cumplir los mismos requisitos que los Subsecretarios y los Secretarios generales técnicos, pero en relación a las funciones específicas de determinadas Direcciones Generales, el Real Decreto que cree dicha Dirección General puede exonerar del requisito de la condición funcionarial y permitir que sea nombrada una persona con experiencia previa en el sector privado. Para los Subdirectores generales es exigible su condición de funcionario de carrera de titulación superior perteneciente inicialmente a la Administración General del Estado, aunque las normas de aplicación pueden admitir la pertenencia a otras Administraciones Públicas.

Respecto de los órganos directivos de la Administración en el exterior, la Ley no contiene ninguna disposición específica remitiéndose a la normativa sectorial reguladora del Servicio exterior.

En lo que se refiere a la Administración periférica, no se establece ningún requisito singular con relación a los Delegados del Gobierno, por lo que únicamente le son aplicables los criterios generales antes analizados. Lo más singular de esta Ley se ha concretado, sin embargo, con relación a la anterior figura clásica del Gobernador civil, que era un órgano de pura designación política y representaba al Gobierno en la Provincia. La nueva Ley lo transforma en el Subdelegado del Gobierno, con nivel órganico de Subdirector gene- 
ral, cuyo nombramiento se efectúa por el procedimiento administrativo de libre designación entre funcionarios de carrera de los cuerpos superiores de las distintas Administraciones públicas.

Sin haberse desvelado en qué va a consistir la aplicación del principio de responsabilidad profesional, personal y directa -que en ningún caso puede atenuar la responsabilidad de la Administración en relación con los ciudadanos-, ni cuáles son las consecuencias de una eventual evaluación negativa de la gestión desarrollada, la LOFAGE establece límites a la libertad de selección de los titulares de los órganos directivos. Pero este paso en pro de la profesionalización no ha resuelto el problema fundamental de la constitución de un nivel directivo como nivel propio de la carrera funcionarial.

En efecto, el cambio de Gobiemo producido en España en 1996 ha supuesto la remoción de varios millares de cargos directivos (se estima que entre 3.000 y 4.000), con la consecuencia de que, al ser funcionarios la inmensa mayoría de ellos, tienen asegurado por Ley que, tras su remoción, ostentan el máximo grado personal de puesto de trabajo (nivel 30), por lo que, de continuar esta tendencia, la generalidad de los miembros de cuerpos superiores acabarían ostentando tal grado máximo. Esta situación de -jefes sin indios. no es en absoluto deseable. Por ello, el sistema de profesionalización de los órganos directivos debe resolver adecuadamente el problema de la futura reinserción en la carrera administrativa de los directivos cesados.

\section{La adaptación permanente de la calidad de los servicios}

Ya la Ley 30/1992, de 26 de noviembre, de Régimen Jurídico de las Administraciones Públicas y del Procedimiento Administrativo Común, había establecido en sus artículos 35 y siguientes una tabla de los derechos de los ciudadanos en relación al funcionamiento de las Administraciones Públicas.

En la reforma del funcionamiento de la Administración General del Estado se ha tenido en cuenta, ya desde las primeras redacciones del Proyecto de Ley socialista, el mandato que la Constitución (art. 9.2) da a los poderes públicos de promover las condiciones para que la libertad y la igualdad del individuo y de los grupos en que se integra sean reales y efectivas y de remover los obstáculos que impiden o dificulten su plenitud.
En la Exposición de Motivos del mencionado proyecto de Ley se hacía una referencia explícita al hecho de que gran parte de los derechos de los ciudadanos dependen directamente del buen o mal funcionamiento de las Administraciones Públicas y que los resultados de bienestar social reclamados por la vía democrática son esencialmente el producto de la actividad pública de prestación e intermediación social. Por ello, con los principios de funcionamiento introducidos en la reforma se pretendia, de una parte, garantizar al ciudadano frente a la inactuación administrativa que le pudiese privar de un servicio público y, de otra, asegurar los resultados del servicio, puesto que en estos resultados se concretan el contenido real de los derechos de prestación.

La actual Exposición de Motivos de la LOFAGE también se reclama en este punto a la efectividad del artículo 9.2 de la Constitución en relación con el 10.1 del mismo texto constitucional que proclama el libre desarrollo de la personalidad humana. De aquí se hace derivar el carácter instrumental de las Administraciones Públicas al servicio de los intereses genèrales de los ciudadanos, que debe constituir el principio básico que justifica su existencia y que debe presidir su entera actividad.

Es de desear, así, que una materia como el funcionamiento interno de la Administración deje de ser concebida como un aspecto secundario del ordenamiento jurídico administrativo y que cobren una relevancia aplicativa los principios legalmente enunciados:

- Eficacia en el cumplimiento de los objetivos fijados.

- Eficiencia en la asignación y utilización de los recursos públicos.

- Programación y desarrollo de objetivos y control de la gestión y de los resultados.

- Responsabilidad por la gestión pública.

- Racionalización y agilidad de los procedimientos administrativos y de las actividades materiales de gestión.

- Servicio efectivo a los ciudadanos.

- Objetividad y transparencia de la actuación administrativa.

- Cooperación y coordinación con las otras Administraciones públicas.

- Efectividad de los derechos de los ciudadanos cuando se relacionen con la Administración.

- Determinación de las prestaciones que proporcionen los servicios estatales, sus contenidos y los correspondientes estándares de calidad.

En el cumplimiento de estos principios se juega la Administración española la partida de su verdadera modernización. 
Desconociendo los objetivos, todo resultado puede presentarse como un éxito y la no cuantificación de las prestaciones elimina en gran parte su posibilidad de control jurídico. Así, la previa programación y planificación, con inclusión de los contenidos y los estándares de calidad de los servicios, opera como parámetro de control y evaluación, de la que se puede hacer derivar responsabilidad para sus gestores y derechos por incumplimiento respecto de los ciudadanos. Se estaría configurando, así, un verdadero proceso de actuación que permita afirmar y controlar los elementos de la objetividad y transparencia administrativa.

\section{La adaptación de la Administración periférica al Estado de las Autonomías}

La reforma de la Administración periférica para su adaptación a la implantación progresiva de las Administraciones autonómicas ha sido objeto de un debate constante en las dos últimas décadas. Se debe recordar a este respecto el R.D. 3117/1980, que reforma el Estatuto de los Gobemadores civiles, y el R.D. 1801/1981, de reforma de la Administración periférica. Estos primeros pasos se completan con la regulación legal de la figura del Delegado del Gobierno (R.D. 2238/1980 y Ley 17/1983), el R.D. 1223/1983, de 4 de mayo, de medidas de reorganización de la Administración periférica del Estado, y los principios contenidos en los artículos 22 y 23 de la Ley 12/1983, de 14 de octubre, del Proceso Autonómico, que proponían una readaptación cíclica de la Administración estatal, tanto central como periférica, en función de los traspasos de medios y servicios acordes con la asunción de nuevas competencias por parte de las Comunidades Autónomas.

El proceso de reforma que conduce a la LOFAGE planteaba ya en el proyecto socialista una unificación de toda la Administración periférica en tomo a las figuras del Delegado del Gobierno y del Gobernador civil. Quedaban a salvo determinados servicios que quedarían no integrados en virtud de sus peculiaridades funcionales de relación inmediata con los ciudadanos y se hacen desaparecer las Delegaciones provinciales de los Ministerios. También se reforzaba la figura del Delegado del Gobierno tanto en su relación con la Administración central, como respecto de sus poderes de dirección sobre el Gobernador civil. Sin embargo, era claro en este Proyecto que esta readaptación de la Administración periférica no implicaba una renuncia a la gestión periférica de las competencias estatales ${ }^{4}$.

La actual LOFAGE incorpora dos nuevos elementos propios. De un lado, el concepto de "Administración única" surgido de una propuesta política de la Comunidad Autónoma de Galicia gobernada por el Partido Popular. De otro, la supresión de los Gobernadores civiles, como representantes políticos del Gobierno en la Provincia, a instancias del nacionalismo catalán, de acuerdo con el pacto de legislatura establecido por el P.P. y CiU.

El concepto de Administración única aboga por convertir a la Administración autonómica en la administración gestora por excelencia, implantando un modelo similar al del federalismo de ejecución. Es decir, que no se trata únicamente de adaptar la Administración periférica estatal a las funciones administrativas reservadas a este nivel público, sino de proceder a transferir de forma sistemática competencias estatales al nivel autonómico, en la medida en que se considere que éste es el más adecuado para realizar dicha gestión 5 .

Este protagonismo de la Administración autonómica se acompaña de una devaluación de la presencia política del Estado en la Provincia, eliminando la figura tradicional del Gobernador civil, que constituía un alto cargo de designación política en representación del Gobierno en dicho territorio y tenía categoría de Director general.

Al margen de las opiniones de tipo político sobre esta reforma, se deben destacar alguna consecuencia e incoherencia del modelo resultante. En efecto, si el modelo final es el de la Administración única, significa que la función esencial de la Administración periférica sería la de servir como mecanismo de control y seguimiento de las competencias transferidas o delegadas por la vía del artículo 150.2. Pues bien, la Ley está ausente de cualquier referencia a este fenómeno de seguimiento de las funciones transferidas.

\section{Conclusiones}

Quizá el elemento de más peso e importancia en la reforma administrativa consista en la conciencia ya instalada en el aparato político español de que la modernización del País y su adaptación a un marco mucho más fluido en el terreno de la economía —cada vez más globalizada-, de la política —cada vez más comunitaria-, y de las garantías sociales -cada vez más necesitadas de racionalización y protección-, no son posibles sin un proceso permanente de modernización de las estructuras administrativas.

Las Administraciones constituyen en Europa las gestoras de la mitad de la riqueza producida por los europeos, por lo que no puede existir un desfase entre las necesidades de la sociedad y las prácticas y principios de actuación de los aparatos burocráticos. Por ello, sin menoscabar los mecanismos de control 
dictados en base a las garantías de los ciudadanos, debe darse cada vez mayor importancia a los aspectos de la organización y el procedimiento administrativo para crear, en primer lugar, mecanismos flexibles, ágiles y transparentes que potencien la consecución de los fines de interés general. Pero, también, la modernización de las formas de funcionamiento, en términos de programación de objetivos cuantificados y del establecimiento de contenidos estandarizados en los servicios de prestación, permite el control global en términos de los principios de eficiencia y eficacia, tanto por parte de las propias Administraciones Públicas, para poder programar adecuadamente de nuevo, como de los colectivos cuyo bienestar depende del buen funcionamiento de los servicios públicos.

La reforma emprendida en España que culmina con la aprobación de la LOFAGE ha puesto a disposición del proceso de modemización algunos instrumentos que deben ser potenciados como la transparencia, la evaluación de la eficacia, la responsabilidad gestora del nivel directivo, la descentralización funcional en Organismos Autónomos y la especialización ministerial en la función gubernativa. Queda al tiempo futuro ser juez del adecuado uso de estos instrumentos.

\section{Notas}

- Catedrático de Derecho Administrativo. Universidad de Castilla-La Mancha.

1 Ley 6/97, de 14 de abril, de Organización y Funcionamiento de la Administración General del Estado (LOFAGE) (BOE) n. 90 , de 15 de abril de 1997.

' Boletin Oficial de las Cones Generales (BOCG) de 21 de octubre de 1995, Serie A, n. ${ }^{n}$ 138-1. Un comentario al conjunto de esta Ley puede verse en la edición del Seminario que sobre dicho Proyecto de Ley tuvo lugar en la Universidad Carlos III bajo la dirección del profesor Luciano PAREjo: Estudios sobre la Administración General del Estado, Universidad Carlos III. Madrid. 1996.

'Boletín Oficial de las Contes Generales (BOCG), de 23 de enero de 1997, Serie A, n. $27-1$.
- La Exposición de Motivos decía con toda claridad: •El Estado mantiene, asi, su presencia institucional en la totalidad del territorio nacional, a través de órganos generales y específicos que pongan de manifiesto a los ciudadanos la responsabilidad política general del Gobiemo, de acuerdo con el modelo de pluralismo políico territorial recogido en nuestra Constitución.

' La Exposición de Motivos de la LOFAGE señala a este respecto: ‘... resulta conveniente introducir en esta Ley el objetivo de la Administración única o común de forma que el protagonismo administrativo en el territorio autonómico lo tenga la Administración autonómica, que también podrá asumir funciones administrativas corespondientes a materias de competencia exclusiva del Estado a parir de las técnicas del arículo 150.2 de la Constitución.

\section{Bibliografia}

ARINo, La Administración institucional. Bases de su régimen juridico, Instituto de Estudios Administrativos. Madrid. 1972.

BAENA DEL ALCAZAR, sa ordenación de la Administración central y periférica y la actividad administrativa, en La Administración en la Constitución. Centro de Estudios Constitucionales. Madrid. 1980.

Beitrín, La élite burocrática española, Ariel. Madrid. 1977.

-De la reforma de la Administración al control de calidad de los servicios públicos, Gestión y Anälisis de Politicas Puiblicas, n. ${ }^{\circ}$ 5-6. 1996.

BETANCOR, Las Administraciones independientes, Tecnos. Madrid. 1994.

Clavero Arévalo, Personalidad juridica, Derecho genetal y Derecho singular de las Administraciones autónomas, Madrid. 1992.

ECHEVARRiA, EEl cambio y la gestión del cambio en la Administración pública, en Modernización administrativa. Oñati. 1989.

GARCIA DE ENTERRIA, La Administración española, Madrid. 1972.

Problemas actuales del Régimen Local español, Instituto Garcia Oviedo. Sèvilla. 2.' ed. 1986.

GaRRIDO Falla, la Administración única: problemática de una obviedad, Revista de Administracion Puiblica, n. ${ }^{\circ} 130.1993$.

JIMÉNEZ DE CISNEROS, LOS Organismos Autónomos en el Derecho püblico español: tipologia y régimen juridico, Instiruto Nacional de Administración Pública. Madrid. 1987.

MARTIN MATEO, voces Ministerio y Ministro, en Nueva Enciclopedia Jurídica Tomo X. 1979.

MARTIN REBOLO, AAnte la reforma administrativa: los Ministros y otros miembros del Gobierno, Revista de Administración Pública, n. ${ }^{\circ} 89.1979$.
MARTIN-RETORTLLO, S. (dir.), Descentralización administrativa y organización politica, 3 vols. Alfaguara. Madrid. 1973.

Administración y Constitución, Instituto de Estudios de Administración Local. Madrid. 1981.

_El reto de una Administración racionalizada. Madrid, 1983.

_ Las empresas públicas: reflexiones del momento presente, Revista de Administración Priblica, n." 126. 1991.

MinSTERIO para las ADMINISTRACIONES PÚBLCAS, Reflexiones para la modermización de la Administración del Estado, Madrid, 1990.

Estudio Delphi. La modernización de los procedimientos de actuación de la Administración priblica, Madrid. 1990.

_La modernización de la Administración del Estado. Los senvicios comunes. Madrid. 1991 .

_ Plan de modemización de la Administración del Estado, Madrid. 1992. Gestión y evaluación de la caliälad de los servicios priblicos, Madrid, 1995.

NIETO, -De la República a la Democracia: La Administración española., Revista Española de Derecbo Administrativo, n. ${ }^{\circ} 11.1976$.

-Burocracia y sociedad democrática, en Jormadas administrativas del INAP. Madrid. 1978.

-Reforma administrativa y modemización de la Administración pública ¿Un problema pendiente?, en Modemización Administrativa Onati. 1989.

__ La organización del desgobiemo, Ariel. Barcelona, 2." ed. 1996.

ORTEGA, La Administración central del Esado, Facultad de Derecho. Universidad Complutense. Madrid. 1982. 
-Administración periférica y descentralización, Documentación Administrativa, n. 214.1988.

-La reforma de la alta burocracia en España., Sistema, n. 107. 1992

.El reto dogmático del principio de eficacia., Revista de Administración Pública, n. 133. 1994. $\overline{1995}$.

.La reforma de la Administración estatal y autonómica, Autonomies, n.” 20.

-La modemización de las Administraciones Públicas, Gestión y Análisis de Politicas Priblicas, n." 5-6. 1996.

PAREjo ALFONSO, *Algunas reflexiones sobre el poder público administrativo, como sistema, en el Estado autonómico: una contribución al debate sobre la llamada Adminis-

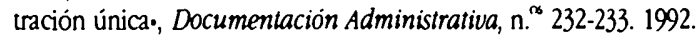

PINAR MAvis, .La Administración periférica del Estado, Revista de Administración Pública, n. 100-102. 1983.

RODRIGUEZ ARANa, La Administración única en el marco constitucional. Santiago de Compostela. 1993.
SALAS, Hacia una reestructuración de la Administración periférica del Estado, Documentación Administrativa, n. ${ }^{\circ} 182.1979$.

TORvos MAS, Administración estatal y autonómica, Autonomies. n. ${ }^{\circ} 2.1995$.

W.AA., Cobiemo y Administración en la Constitución, 2 vols. Instituto de Estudios Fiscales. Madrid. 1988.

WV. AA., Administración y Constitución: El principio de eficacia, (monográfico). Documentación Administrativa, n." 218-219. 1989.

VV.AA., •Administración y Constitución: el principio de jerarquía, (monográfico). Documentación Administrativa, n. 229.1992.

VV.AA., AAdministración y Constitución: el principio de coordinación-, (monográfico). Documentación Administrativa, n." 230-231. 1992.

VV.AA., Administración instrumental. Libro bomenaje a M. Clavero Arévalo, 2 vols. Civitas/Instituto Garcia Oviedo. Madrid. 1994.

VV.AA., Estudios sobre la Administración General del Estado. Seminario sobre el Pro. yecto de Ley de Organización y Funcionamiento de la Administración General del Estado (LOFAGE), ed. a cargo de Luciano Parejo. BOE/Universidad Carlos III. Madrid. 1996. 